\title{
Virtual Reality in Science Education: A Descriptive Review
}

\author{
Alper Durukan ${ }^{1 *}$, Huseyin Artun², Atilla Temur ${ }^{1}$ \\ ${ }^{1}$ Department of Science Education, Faculty of Education, Van Yuzuncu Yil University, Van, Turkey \\ ${ }^{2}$ Department of Elementary Education, Faculty of Education, Van Yuzuncu Yil University, Van, Turkey \\ *Corresponding Author. a@,alperdurukan.com
}

\begin{abstract}
The term "Virtual Reality" currently refers to a profound sensory immersion of the user in a synthetically generated virtual environment. It is foreseen that virtual reality will gain a substantial role in the instruction of science. In this literature review, the purpose was to investigate the research on the utilization of virtual reality in the science education context, according to several criteria. The articles published in peer-reviewed journals and academic conferences/symposiums that are available in the databases of ERIC, WOS, and Google Scholar have been reviewed. Consequently, a total of 30 eligible articles reviewed and findings presented under every respective criterion. Partially, findings revealed the dominance of journal article type publications, the USA and Turkey found to be most prominent origins, experimental studies being preferred mostly, undergraduate students and pre-service teachers were the most studied groups, the contexts of the studies were prominently general, and the learning outcomes investigated mostly.
\end{abstract}

Keywords Science education, Virtual reality, Instructional technology, Science laboratory instruction, Literature review

\section{INTRODUCTION}

Instructional technologies (IT) are a valuable tool in the arsenal of instruction in terms of constraints such as time, accessibility, and cost. IT is particularly suitable for increasing student interest, reducing the time needed for classroom activities, and supporting educational efficiency (Yumuşak \& Aycan, 2002). When used in the instruction of science, IT may be considered as the main actor in bringing scientific findings to a solid-state and articulate the situations that unobservable with the senses (Linn, 2003).

In the past, virtual reality (VR) has been relatively under-emphasized in education due to its' high cost and limited availability (Checa \& Bustillo, 2019). In time, the advancements of technology led to a new understanding of IT. Moreover, the paradigmatic shift in terms of the utilization of technology in science education facilitated the emergence of innovative instructional technologies. As the environments in which information transferred are changing, the incorporation of such technologies in science education has been gaining importance. Today, wearable technologies and augmented reality and VR can be listed as the most explicit examples of innovative technologies (Çalışkan, 2017). In the context of education, VR may be described as an interface that presents a sufficient sensory immersion to users in an artificial environment generated by a computer and/or mobile device (Lee, Wong, \& Fung,
2010; Mora, Martín-Gutiérrez, Añorbe-Díaz, \& GonzálezMarrero, 2017).

As a tangible demonstration, Trindade, Fiolhais, and Almeida (2002) defined VR as an interface that embodies conceptual models. They also classified the essential components of the VR environment as Immersion, Interaction, and Engagement, as demonstrated in Figure 1.

The Immersion component refers to the convincing properties of VR that make users perceive a sufficient existential embodiment (Bowman \& McMahan, 2007). This authentic perception results in a relatively genuine occasion by addressing multiple sensory inputs. Secondly, Interaction refers to the capability of simultaneous obtainment and manipulation of the intended experience by enabling users to manipulate the virtual environment (Nalbant \& Bostan, 2006). VR makes it possible for the users to interact with that environment as in real life, which in turn facilitates learning-by-doing. Finally, Engagement translates into individuals' voluntary participation to experience the VR environment (Trindade, Fiolhais, \&

Received: 13 December 2019

Revised: 23 April 2020

Published: 15 July 2020 


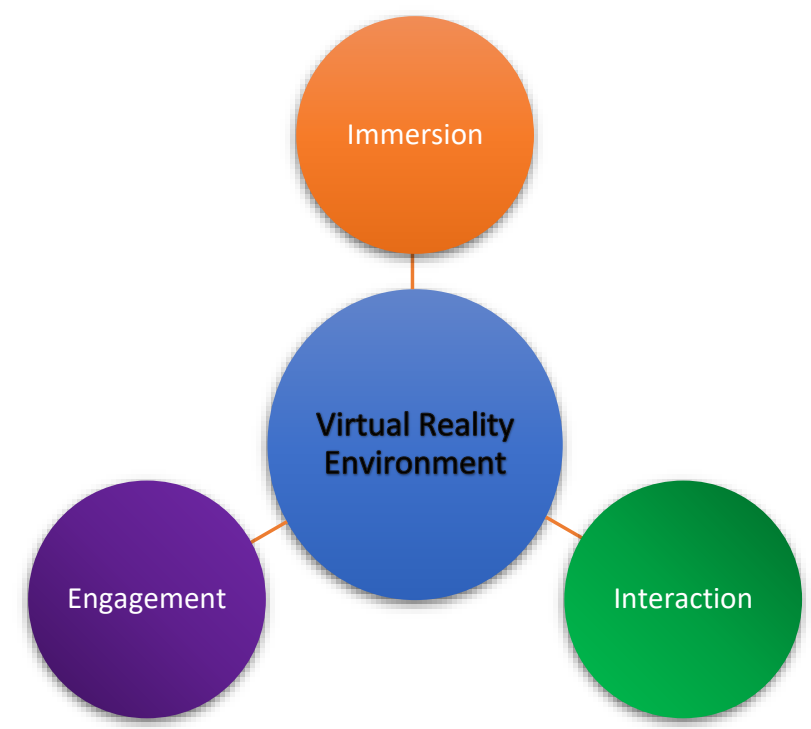

Figure 1 The components of the VR environment (Trindade, Fiolhais, \& Almeida, 2002)

Almeida, 2002). Learners immersed through a realistic sensory embodiment tend to participate willingly in educational activities within the VR environment.

The technological advancements also led VR interfaces to develop in terms of their functions and feasibility. Capabilities of predecessor computer-based VR, which regarded as immersive in the past, nowadays fall short compared to the current state of Immersive VR. Immersive VR can be defined as an interface that authentically mimics real-world settings regarding visual, perceptional, and functional dimensions. When current opportunities are considered, it would be more appropriate to place obsolescent screen-based interfaces within the category of computer simulations. Mora, Martín-Gutiérrez, AñorbeDíaz, and González-Marrero (2017) suggested three categories of interfaces in which virtual and augmented reality scenes are created and experienced: (a) Smartphones mounted on headsets, (b) Stand-alone head-mounted displays, (c) Augmented reality devices.

It could be concluded that science instruction and laboratory practices enriched with VR facilitate not only the consumption of authentic learning situations but also the creation of them. Allcoat and von Mühlenen (2018) emphasize the feasible promises of VR and state that VR is more than an additive to current practices: it is an interface that can expose learners to authentic learning experiences. Moreover, rather than limiting the benefits for learners only, making use of this potential could provide meaningful opportunities for the pre-service and in-service training of science educators as well. As VR is gradually becoming more accessible, research on VR in the education of science and thought to be emphasized more in time. Therefore, this review aims to investigate the research on the implementation of VR in science education by evaluating them according to several criteria.

\section{METHOD}

The study conducted as a literature review. Literature reviews aim to examine scientific publications carried out on a specific field or subject area (Galvan \& Galvan, 2017). In the present study, studies incorporate the use of VR technologies in the field of science education systematically investigated. Findings obtained from this investigation have been presented respectively

\subsection{Screening of the databases}

To reach eligible studies, the databases of ERIC, WOS (Web of Science), and Google Scholar were used. The following joint search query used to reach relevant research on VR in instruction science and sub-disciplines of Physics, Chemistry, and Biology: Virtual reality AND science education OR physics education OR chemistry education OR biology education.

\subsection{Criteria for the eligible studies}

The eligibility of the studies for investigation determined according to several inclusion conditions. The reasons for the exclusion of irrelevant papers were as follows: (a) Not being relevant to the instruction of science and its sub-disciplines of Physics, Chemistry, and Biology. (b) Not being subjected to a peer-reviewing process such as in academic journals or conference publications: Therefore, even being contextually relevant, publications such as books, book chapters, and reports have been excluded. Consequently, a total of 30 articles focusing on the use of VR technology in science education found to be eligible and thereby investigated.

\subsection{Classification of the Studies}

The eligible studies investigated according to the following criteria: (a) Publication type, (b) Country origin, (c) Genre, (d) Published year, (e) Keywords used, (f) Method, (g) Sample or participant group, (h) Context, (i) Investigated variables and situations. 


\section{RESULT AND DISCUSSION}

The findings presented under respective sections.

\subsection{Types of publications}

Figure 3 represents the distribution of the publication types. Among reviewed studies, 23 papers $(77 \%)$ were articles published in peer-reviewed journals, and the remaining seven papers $(23 \%)$ were either abstracted or full-text manuscripts published in the proceeding booklets of academic conferences or symposiums.

\subsection{Country origins}

Figure 4 presents the country origins of the investigated studies. Determination of country origins conducted concerning the individual characteristics for each of the reviewed publications. For the experimental studies, either the country in which respective intervention(s) held or accommodated the participants, were considered. For nonexperimental studies and studies with multiple authors, corresponding authors' institutions taken as the basis.

As seen in Figure 4, the USA ranked first in number by being the origin of nine studies, which was followed by

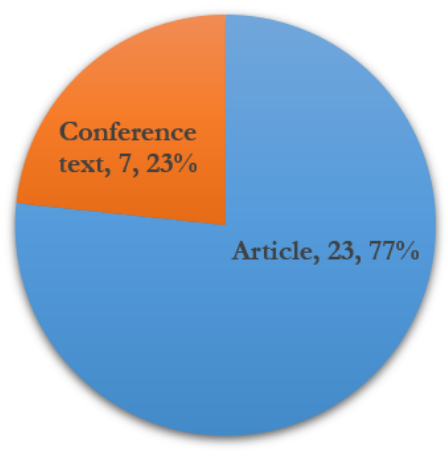

Figure 3 Distribution of publication types
Turkey with seven studies, and Taiwan with three studies coming third. Australia, Spain, Israel, Sweden, Canada, Malaysia, Portugal, Serbia, New Zealand, and Greece each being origin of one study on the use of VR in science education, per se.

\subsection{Genres of the studies}

Figure 2 shows the distribution of the studies by their genres. Among all, 15 studies (50\%) classified as Experimental, which utilized a particular manipulation regarding VR-assisted science instruction to influence specific variable(s). Eight studies $(27 \%)$ classified as Descriptive introduced potential outcomes, available opportunities, and materials for the use of VR in education, either generally or science education specific.

Moreover, four studies (13\%) categorized as Material, which introduced the VR material developed and discussed the potential application areas. Lastly, three $(10 \%)$ papers classified as review, which utilized a systematic examination of the literature.

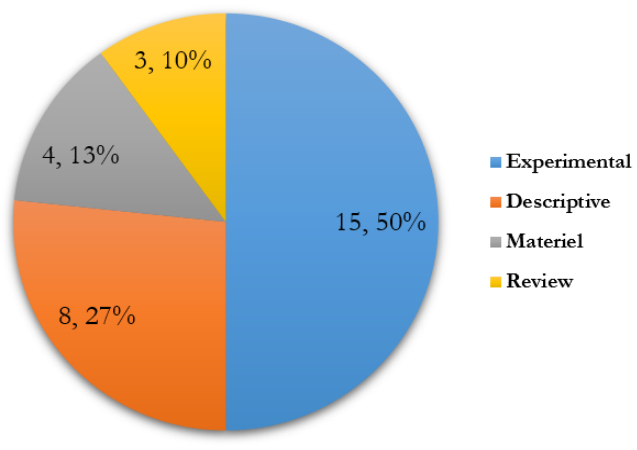

Figure 2 Distribution of reviewed studies by genres

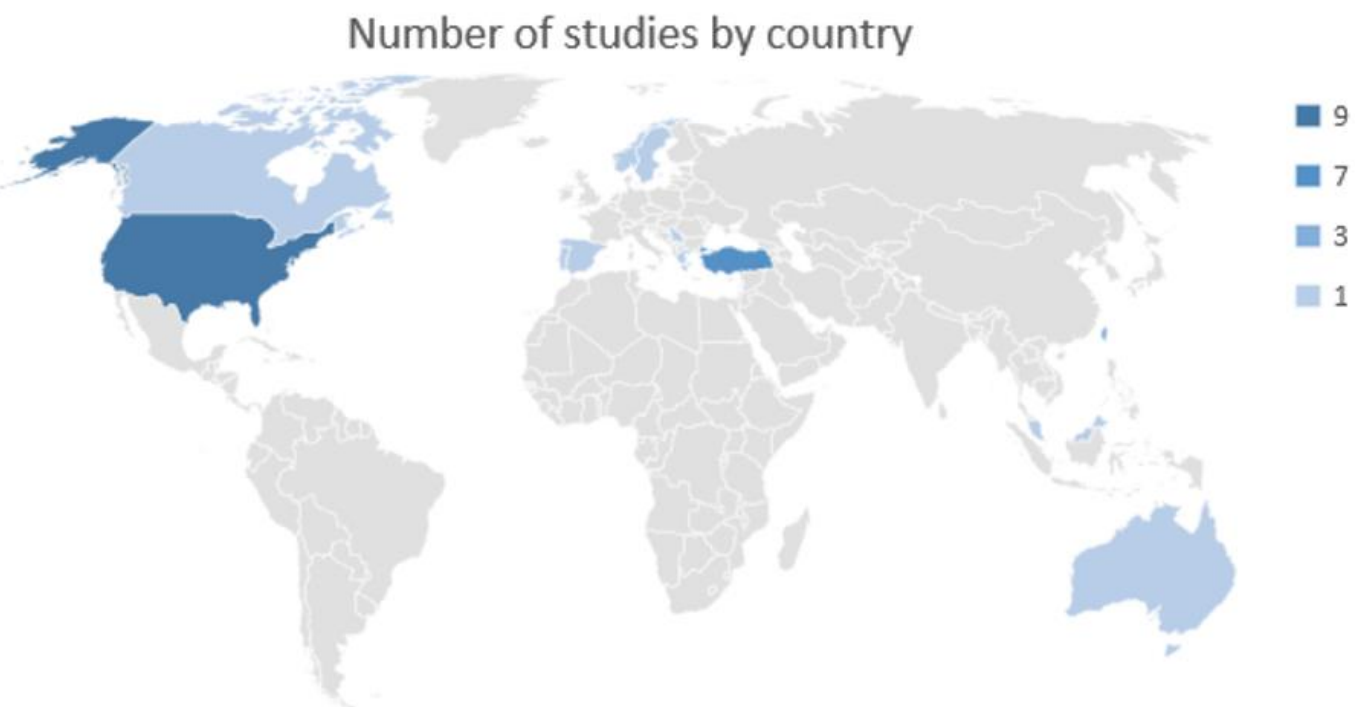

Figure 4 Distribution map of the studies concerning their country origins 


\subsection{Publication Dates}

The grouped publication dates of the studies presented in Figure 6. There was one study conducted between 19901994, one study between 1995-1999, three studies between

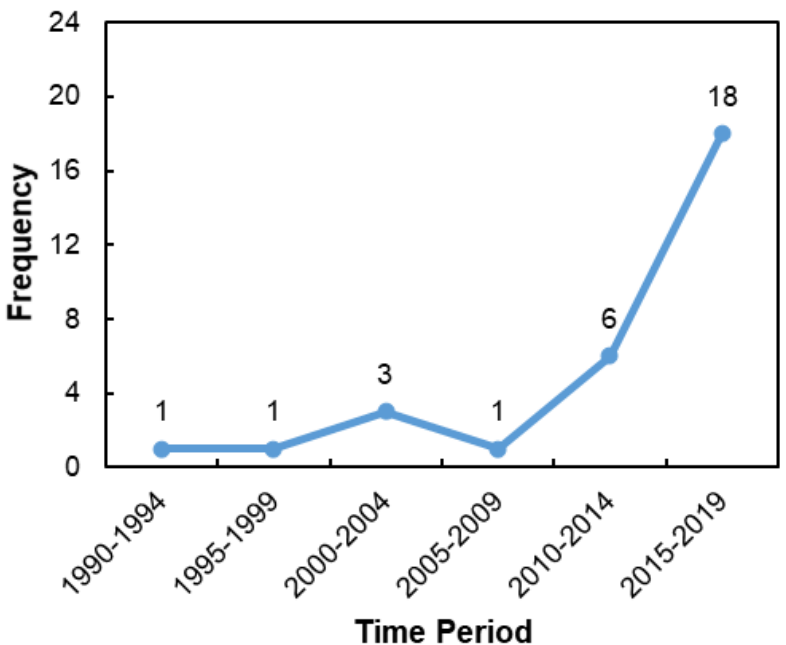

Figure 6 Frequency of studies regarding their time-period of publication
2000-2004, one study between 2005-2009, six studies between 2010-2014 and 18 studies between 2015-2019.

\subsection{Keyword usage}

Figure 5 presents the frequencies of keywords of the studies that adjusted by acknowledged terminology in the literature. Findings revealed a vast variation in the keywords, hence, infrequent and similar keywords grouped by the acknowledged terminology used in the literature. It is seen that 19 keywords used in the context of Virtual reality, seven keywords in Instructional technologies six keywords in Chemistry, Individual factors, Learning outcomes and Virtual worlds, five keywords in Materials and tools and Learning experience and four keywords in the contexts of Augmented reality, Education and Virtual laboratories. Also, keywords for the settings of Biology, Interactive learning environments, Science teaching, Immersive education, and Methods used in three studies. Lastly, the keywords used in the contexts of Practices in subject areas, User interfaces, Pre-service teachers, Pedagogical situations, Applied laboratories, and Constructive methods were used only once, per se.

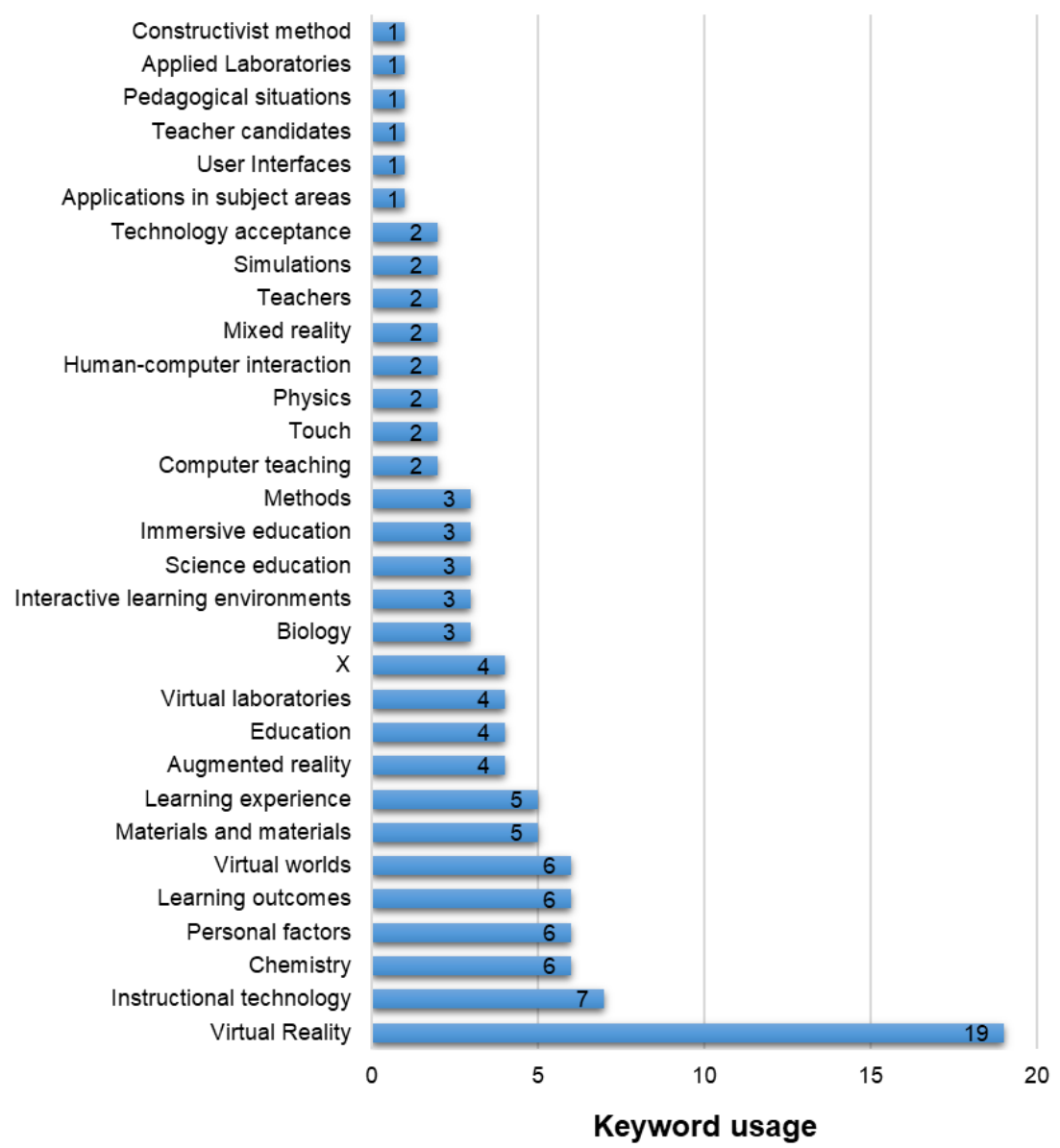

Figure 5 Keywords used in the studies 


\subsection{Methods of the reviewed studies}

The distribution of the research methods utilized in reviewed studies is presented in Figure 7 . The research method not explicitly mentioned in 14 studies $(46 \%)$ hence shown as $X$ in the graph. Apart from this, the most prominent method found to be Quasi-experimental, utilized in eight studies (27\%). Moreover, there were two studies (7\%) designed as Pre-experimental, two studies (7\%) conducted as a survey, and two studies $(7 \%)$ conducted with Mixed design, which utilizes both qualitative and quantitative procedures. Lastly, there was one study (3\%) conducted as Meta-analysis, and one study (3\%) found to be Qualitative.

\subsection{Participants}

Figure 8 shows the distribution of sample \& participant groups or data sources of the reviewed studies. Eleven studies $(34 \%)$, which represented the code of $X$, did not explicitly include/state a participant group or a data source. It also is seen that five studies $(15 \%)$ carried out with Undergraduate students from various departments, and four studies $(12 \%)$ conducted with Pre-service teachers. Although pre-service teachers are undergraduate students, they

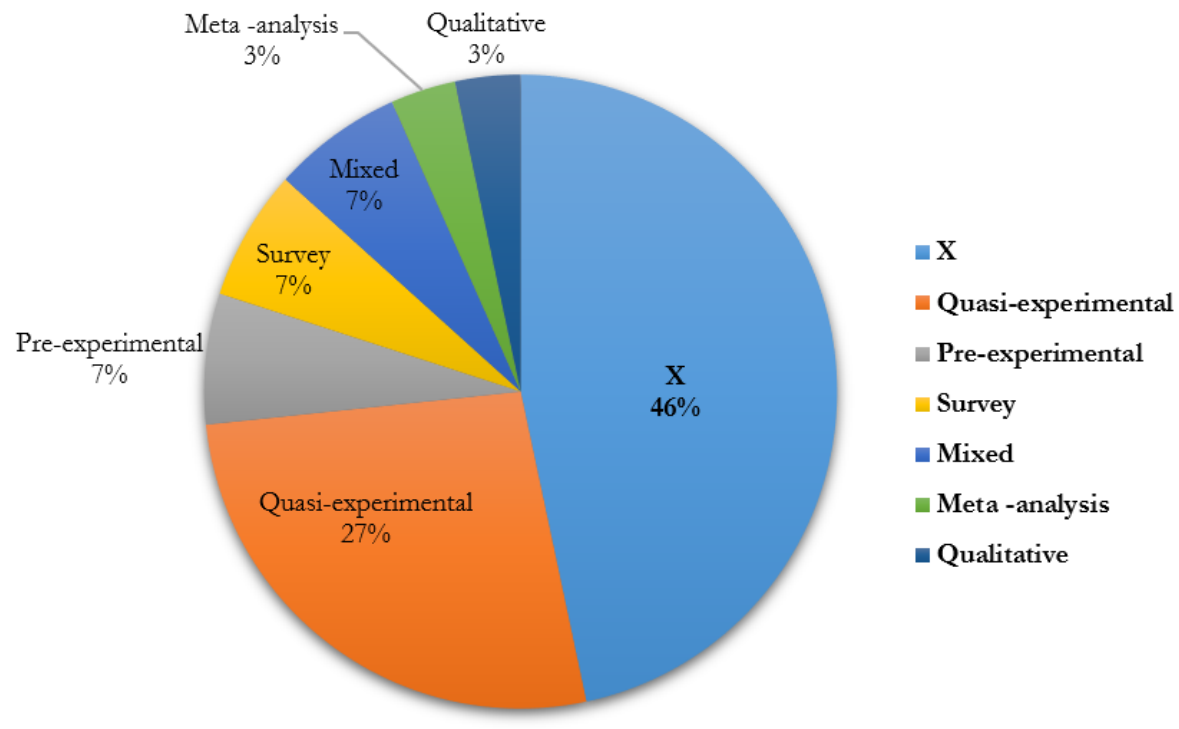

Figure 7 Distribution of the research methods

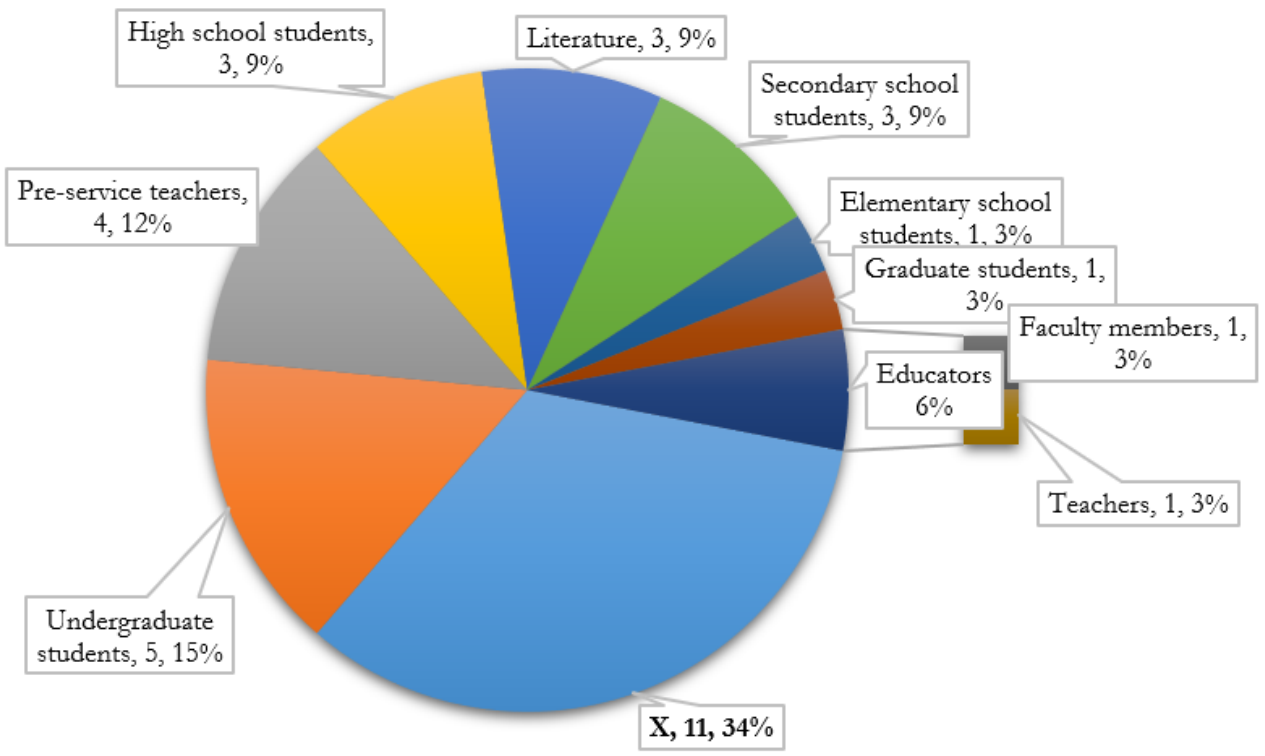

\section{$\mathrm{X}$ \\ - High school students \\ - Elementary school students \\ Teachers}

- Undergraduate students

- Literature

n Graduate students
घ Pre-service teachers

- Secondary school students

Faculty members

Figure 8 Distribution of the participants 


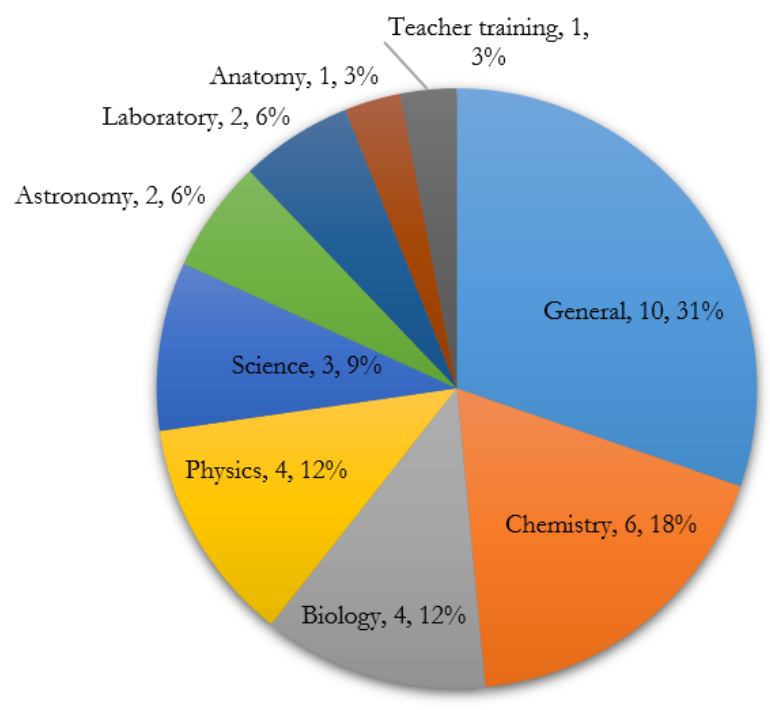

Figure 9 Distribution of the contexts

presented apart from the undergraduate students to reflect the context of teacher training better. Also, three studies obtained the data from the literature, which carried out using descriptive or survey research to examine a relevant particular research topic. Lastly, there was one study carried out with Elementary school students (\%3), one study with Graduate students (\%3), one study with Faculty members (\%3), and one study with Teachers (\%3). It was considering the parent category of Educators, two studies in total conducted with teachers and faculty members $(6 \%)$.

\subsection{Context}

Figure 9 presents the distribution of the contexts emphasized in the reviewed studies. Concerning the instructional contexts, ten studies $(31 \%)$ classified as
General, which focuses on the use of VR by briefly mentioning the instruction of science as well as other disciplines in a non-specific manner. Moreover, six studies $(18 \%)$, which were carried out within the context of Chemistry, focused on the role of VR technologies in teaching chemistry-related topics. Also, there were four studies $(12 \%)$ carried out in the context of Biology and Physics to examine the use of VR in the instruction of these disciplines. It seems that the context of Astronomy covered the topic of celestial bodies in two studies $(6 \%)$. In two studies $(6 \%)$ in the context of laboratory, science laboratory practices in a virtual environment were covered in general by not focusing on a specific topic. Lastly, there was one study (3\%) carried out in the context of Anatomy, focusing on animal physiology, and one study $(3 \%)$ in the context of Teacher training, investigating the use of $\mathrm{VR}$ in the pedagogical practices of pre-service teachers

\subsection{Variables and situations}

Figure 10 presents the frequencies for each investigated variable and situation among the reviewed studies. It was seen that 13 studies, which coded as $X$, did not examine any variable or situation. Following this, six studies measured the participants' Attitudes towards VR-assisted instruction, and four studies measured the influence of VRassisted instruction on participants' Technology acceptance.

Moreover, three studies measured the outcomes in the variable of Spatial skills through VR-assisted instruction, and three studies investigated outcomes in Self-efficacy of participants' VR-assisted instruction as well as obtained qualitative data on Participant opinions. Furthermore, two studies examined the influence of instruction supported with VR on Retention to determine if the learning gains of participants have remained over time. Likely, two studies

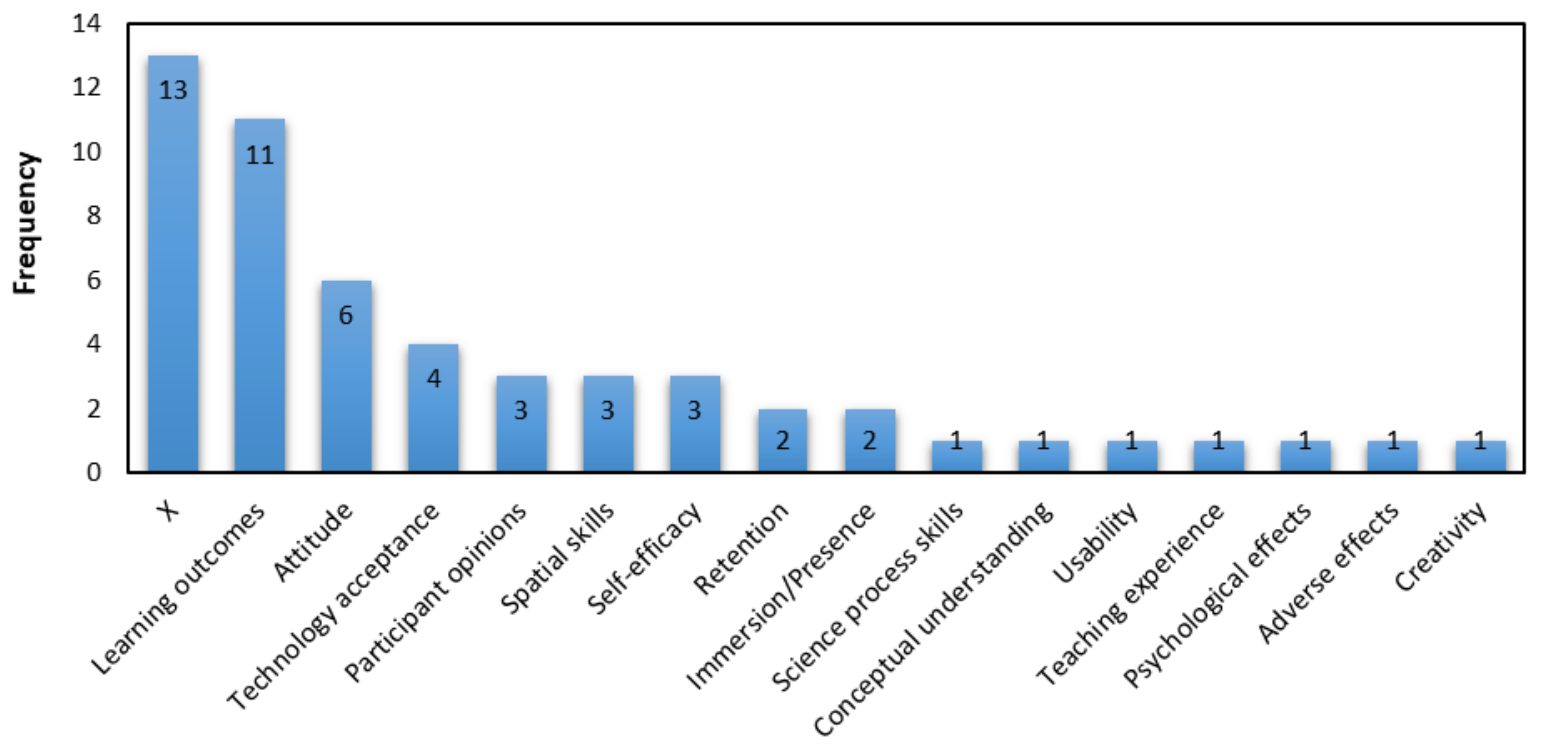

Variable / Situations

Figure 10 Variables and situations examined 
investigated the perceived Immersion/presence experiences of participants in educational VR environments. Lastly, there was one study per se for following variables: Science process skills, Conceptual understanding, Usability of VR in education, Teaching experience investigated through the qualitative data on VR-assisted instruction, Psychological effects and Adverse effects of the usage of VR in science instruction, and lastly qualitative data on opinions towards Creativity in the instruction enriched by VR.

It seems that in terms of the type of publications, the primary research being journal articles, in turn, abstracts and full-texts published in proceeding books of conferences and symposiums, were scarce in comparison. In terms of publication type, Mikropoulos and Natsis (2011) examined the studies carried out on virtual educational environments published between the period of 1999-2009. The researchers found that the majority of studies were articles published in peer-reviewed journals, whereas studies proposed in conferences were rare in comparison. Concluding the similarity in findings, it could be stated that published research on VR-assisted science instruction was more evident in peer-reviewed journals rather than manuscripts proposed to academic conferences or symposiums. This tendency can be interpreted as that the emergence of the VR-assisted science education research is still in progress, and the first remarks of this progress are evident in the peer-reviewed journals. Besides, adequate utilization of VR in the educational contexts requires a relatively rigorous effort, time, and resources. Hence, it is understandable that the researchers prefer to seize their extensive interventions on VR-assisted science education in the high standing publication options.

Concerning country origins, research on VR-assisted science instruction conducted mostly in the USA and followed closely by Turkey. Remaining origins found to be Taiwan, Australia, Spain, Israel, Sweden, Canada, Malesia, Norway, Portugal, Servia, New Zealand, and Greece, respectively. Scimago Lab (2019)'s revelations are similar concerning the country origins of the e-learning studies published between 1996-2017, which also reveals the USA's lead in the research accommodation on instructional technologies. Moreover, a plentiful number of developing countries also found to accommodate relevant research similar to the developed countries. This result bears the impression that there is an international emphasis on the research on the utilization of innovative technologies in instruction. From the perspective of VR, this situation is being prominent, especially in the field of science education. For developing countries, It is entirely reasonable to benefit from the experiences and parallel strategies of developed countries (Hamidi, Ghorbandordinejad, Rezaee, \& Jafari, 2011) in the manner of the emphasis on the instructional technology.

Findings on study genres revealed the dominance of experimental research on VR-assisted science education.
Following this, descriptive studies also found to be abundant in this topic. Literature reviews, on the other hand, found to be the most underrepresented genre among all. Hew and Cheung (2010) examined studies on the use of three-dimensional immersive virtual worlds concerning K-12 and higher-level education. Similarly, they classified the accessed studies as Descriptive and Experimental. They reported an apparent preference and relatively balanced abundance for both, compared to the literature reviews. The preference for experimental and description-aimed research is evident in the findings of this review. The order of this preference may not remain the same for all. In another systematic review of research on the use of virtual reality environments in education, Kim, Lee, and Thomas (2012) reported the prominence of descriptive studies over experimental research. However, their findings revealed a gradual increase in the number of experimental research over time.

Concerning the publication dates of the studies, the number of publications found to increase since the year 2000. Moreover, most of the studies found to be published between 2015-2019. Although not being exactly VR; Akçayır and Akçayır (2017) reviewed the studies on the use of augmented reality in education. They reported a similar trend regarding the increase in publications over time. The researchers also stated that this increase began to accelerate since 2013, and incrementally continued since then. Turning back to the diffusion of VR, this process is still in progress for educators. As the instructional use of the VR becomes a more common practice, it is foreseen that this number will increase even more in the following years.

Regarding keyword usage, it seems that the cluster of the keyword on Virtual reality used the most, followed by Instructional technologies. Similarly, Liu et al. (2017), who used the bibliometric analysis to examine the studies on the use of VR in education that published between 1995-2016, reported that the Virtual reality was the most frequently used keyword, and followed by Interactive learning environment. The researchers also reported that, when viewed from the interdisciplinary perspective, the contents related to the discipline of Chemistry were the most abundant in used keywords. At the same time, the occurrences of Biology and Science ranked second. Besides, they noted that the keywords related to the discipline of Physics found to be scarce among the disciplines. This conclusion supports our results regarding the abundance of discipline-specific terms, in identical order. Another crucial point regarding keyword usage in the studies is an emphasis on the situations and variables observed in relevant studiesbesides, terms referring to certain variables also evident such as; Individual factors, Learning outcomes, and Learning experience. The use of the variables in the keywords section may be attributed to the intention of the authors to make their study more accessible for readers who screen the literature by investigated variables of the studies. Apart 
from that, four studies found to be lacking the keywords entirely.

It is noteworthy that a remarkable proportion of research lacks an explicit statement of the research method. For remaining studies, the dominance of experimental methodology may also outshine as studies requiring a clear statement of research method are thought to be aimed at either description or the development of educational VR materials. Moreover, the most prevalent type in experimental studies was the quasi-experimental design. Concerning this, Jensen and Konradsen (2017), examined the research on immersive VR technologies with headmounted displays in education and training contexts The authors reported that the most common method applied in the quantitative studies was the quasi-experimental design. This preference somewhat understandable as for the educational research, random assignment of the subjects might not be feasible in most circumstances to conduct true-experimental interventions. Also, researchers stressed the scarcity of mixed and qualitative methodologies in the research of VR-assisted education, which supports our present findings.

The findings revealed that the majority of the studies did not explicitly present a participant group or sample like it has been in the methods. The least preferred groups included Elementary school students and Graduate students. In another systematic review on the use of VR in education, Kavanagh, Luxton-Reilly, Wuensche, and Plimmer (2017) similarly reported that the studies on VR-assisted education have mostly been conducted with students from undergraduate and graduate levels. In another study carried out to examine the use of a three-dimensional virtual world game called Second Life in education, Inman, Wright, and Hartman (2010) found that the studies towards the contexts of undergraduate and graduate-level instruction were more prominent in comparison. These studies support our findings regarding the under-emphasis in the literature on the use of VR in the education of the early age groups, which thought to reveal a potential gap in this manner.

The reviewed studies found to mainly emphasize a General perspective in the use of VR in science education. This perspective manifests itself in the prominence of the studies on the use of VR in the instruction of multiple disciplines, rather than focusing on a specific discipline, subject, or concept. The fact that the prominence of the General context may also relate to the abundance of descriptive studies that tend to tackle the use of VR in education broadly. Among discipline-specific studies, the fact that the instruction of the chemistry, biology, and physics being studied more than the instruction of science itself could be related to the subjects' age groups and education levels, which scarce in terms of early grade levels. The science course taught in the levels of elementary and secondary school grades, while chemistry, biology, and physics courses taught as individual courses starting from the high school grade levels. Moreover, further specialization under these disciplines is also evident in the upper levels of education, especially starting from the undergraduate level. As this situation applies to the majority of international educational policies worldwide, it reveals the holistic relationship between the findings. The preferences on the participants and studied contexts appear to related to this situation, which in turn revealed itself not only in the methods but also in the used keywords as well.

As a substantial part of science education, laboratory practices have a central place in the research on instructional technology. In this review, studies on laboratory found to mainly implement a simulation of laboratory facilities in a complete VR environment rather than focusing on the applications, experiments, or visualizations under specific topics. Innovative technologies that allow authentic three-dimensional representations such as augmented reality (Yen, Tsai, \& Wu, 2013) and VR (Barnett et al., 2005), has a great potential in providing concrete observation of the phenomena related to the investigations in science laboratory courses. According to Tuysuz (2010); the difficulty in carrying out experiments at schools that lack laboratories or laboratory equipment could be attenuated by technology. Besides, the author concluded that the virtual chemistry laboratory facilitated the achievements and attitudes of students. In parallel, a VR assisted analytical chemistry instruction found to not only enhance students' laboratory practices but also facilitate their research skills (Bortnik et al., 2017). For the case of the biology laboratory practices, It seems possible not only to examine the physiology of a wide variety of living beings in a precise and detailed manner with VR but also to overcome the financial and ethical constraints in this context. However, although virtual laboratories provide accessibility and replicability, they cannot entirely create the feeling of existence experienced by students in traditional laboratories (Ma \& Nickerson, 2006). Not casting aside the traditional instruction, but seamlessly utilizing technologyenhanced instruction would facilitate the traditional instructional practices as well (Young \& Nichols, 2017). In time, VR-assisted science education thought to lead the science laboratory practices to be more accessible and engaging thanks to their immersive interfaces. The feasibility of VR-assisted laboratory instruction may bolster the boundaries of physical laboratories, especially with a careful and adequate focus on the domain-specific concepts under the topics of science courses.

It should be stressed that the feasible utilization of VR in science education demands component teachers, especially in terms of their technological-pedagogicalcontent knowledge. In this review, the context of Teacher training constituted only the focus of one study, which orientated towards the pedagogical competencies of pre- 
service teachers in multiple branches. One of the promises of VR in the training of teachers argued to be related to its' potential of facilitating pre-service teachers' self-efficacy beliefs (Durukan, 2018; Nissim \& Weissblueth, 2017) and contributing to pre-service teachers' pedagogical competencies in terms of providing authentic teaching experiences (Durukan, Temur, \& Artun, 2018). Concerning these, the context of pre-service science teachers' training needs more emphasis in the research on VR-assisted science education.

The majority of the studies reviewed had not an explicit statement of the methods used; hence, they did not include any experimental structure to examine a variable or situation. One of the potential factors of this may be the prevalence of descriptive and material developmentoriented studies. Moreover, this result also reveals a general lack of intervention in VR-assisted science education research. Also, the tendency to cover a broad context may be related to the prominence of studies that were lacking a dependent variable. In interventional studies, the prominence of quantitative investigations could be associated with the prevalence of Quasi-experimental and Preexperimental designs. Among experimental interventions, Academic achievement was dominant in terms of examined variables. Opposingly, some of the critical outcomes for science literacy, such as Science process skills, Conceptual understanding, as well as Teaching experience of it, was found to be examined only once, being one study for each. Durukan (2018) claims that laboratory practices enriched with immersive VR could contribute positively to the development of science pre-service teachers, science process skills, and, especially the observation, which is considered to be one of the fundamental skills. Padilla (1990) even may develop using low-end VR in the science laboratory. Next, although there is a common thought that VR may develop a conceptual understanding (Lee \& Wong, 2008), there is still a need for a conclusion in this regard (Whitelock, Brna, \& Holland, 1996). The fact that there a limited number of studies examining the variables of ability, teaching experience, psychological effects, creativity, and adverse effects gives the impression that the affective aspect of VR may not be widespread in the research of science education. It hoped that the ongoing diffusion and growing accessibility of VR would result in an emphasis on the outcomes in the affective domain over time.

\section{CONCLUSION}

Papers on VR-assisted science education majorly abundant in the peer-reviewed journals, compared to the conference \& symposium publications. Whereas this can be interpreted as a good indicator, it can also be concerning as the peer-reviewed journal publications require relatively more extensive labor and sufficient experience on the research methodology that is especially emerging researchers could initially lack. That alone can hinder the progression of the literature on VR-assisted science education. In order to ensure the fruitful interventions and practices to emerge, it is suggested that the conferences and symposiums specifically on the use of innovative technologies in science education should be established. Besides, emerging researchers and graduate students should be encouraged to tackle this matter and share their insights with researchers of the field in these conferences.

The growing emphasis on the VR-assisted science education is evident internationally when looked into the publication dates and country origins of the reviewed studies. Concerning the promises of VR in making unreachable instructional practices more accessible in science, it is suggested for the researchers of underdeveloped and developing countries primarily to focus on the use of low-end VR interfaces such as Google Cardboard in the context of science education. The awareness towards that VR does not have to be utilized through costly and hard-to-reach settings in the classrooms can soothe the potential concerns of the researchers. Therefore, this understanding may bolster the literature in terms of feasible outcomes and conclusions from a wide variety of demographical settings.

Genres and the further classification of them in the name of types reveal an abundance of empirical research and description for potential uses. Similarly to the emergence phase of all innovative technologies, the diffusion of VR in the consumer market is still in the establishment phase. Once this diffusion saturates, VR thought to be will be more accessible for consumers than ever. As a result of this accessibility, the growing number of empirical research may facilitate the richness of implications concerning VR-assisted science education. However, the scarcity of material development and review research on these topics demands more attention from the researchers. Even this review thought to help researchers to address potential gaps in the literature. More extensive review and meta-analysis investigations that have a broader coverage may further benefit to the field in this manner, therefore encouraged. In turn, these implications may guide the emerging research and translate into meaningful contributions to the literature.

The situation revealed in the diverse spectrum of terms used as keywords on the research on VR-assisted science education raises concerns regarding the accessibility and establishment of the relevant literature. Even for review, it has become a necessity for the researchers to group infrequent and related keywords by the acknowledged terminology. In this respect, to ensure the accessibility of the studies for the target audience(s), emerging research should be encouraged to abide by common terminology, especially concerning the used keywords.

The findings regarding used methods examined variables and studied participants revealed an irregularity regarding the methods section of the research on VR- 
assisted science education. These fundamental components of the research found to be lacking an explicit and clear statement in most of the reviewed papers, although they are regarded as among the basics of the research methods. In addition to this, the qualitative and mixed methods, examinations on affective domains, and the participants from early-age groups appear to be underemphasized. Therefore, it is explicitly stressed that the researchers should rigidly determine their variables and explicitly state research methodologies in their reports. Lastly, it is suggested that for the emerging research to focus more on the mixed and qualitative inquiries with the participants of early-age groups and emphasize the affective properties of VR in science education more.

Lastly, there is no doubt that investigating the reflections of VR-assisted science education practices not only crucial for learners but also vital for science educators. Therefore, especially in terms of the pre-service science teachers, the incorporation of innovative technologies in the science courses should be integrated more in the training practices, not only for the sake of the research but also for the practice.

The implications of emerging research as the practitioners have been presented for the joint conclusions derived from this review, respectively. These implications ought to facilitate not only the research on the use of VR in science education but also aid science educators to gain valuable insights in terms of using VR in science classrooms.

\section{REFERENCES}

Akçayır, M., \& Akçayır, G. (2017). Advantages and challenges associated with augmented reality for education: A systematic review of the literature. Educational Research Review, 20, 1-11. doi:10.1016/j.edurev.2016.11.002

Allcoat, D., \& von Mühlenen, A. (2018). Learning in virtual reality: Effects on performance, emotion and engagement. Research in Learning Technology, 26(0). doi:10.25304/rlt.v26.2140

Barnett, M., Yamagata-Lynch, L., Keating, T., Barab, S. A., \& Hay, K. E. (2005). Using virtual reality computer models to support student understanding of astronomical concepts. Journal of Computers in Mathematics and Science Teaching, 24(4), 333-356.

Bortnik, B., Stozhko, N., Pervukhina, I., Tchernysheva, A., \& Belysheva, G. (2017). Effect of virtual analytical chemistry laboratory on enhancing student research skills and practices. Research in Learning Technology, 25(0). doi:10.25304/rlt.v25.1968

Bowman, D. A., \& McMahan, R. P. (2007). Virtual reality: How much immersion Is enough? Computer, 40(7), 36-43. doi: $10.1109 / \mathrm{mc} .2007 .257$

Çalışkan, E. (2017). Eğitimde yenilikçi teknolojilerin kullanımı açısından Türkiye'de son beş yll içerisinde (2011-2015) tamamlanmış lisansüstü tezlerin incelenmesi. Journal of Human Sciences, 14(1), 496505. doi:10.14687/jhs.v14i1.4169

Checa, D., \& Bustillo, A. (2019). A review of immersive virtual reality serious games to enhance learning and training. Multimedia Tools and Applications, 79(9-10), 5501-5527. doi:10.1007/s11042-019-083489.

Durukan, A. (2018). Sanal gerçeklikle zenginlestirilmis ögrenme ortammmn fen bilimleri ögretmen adaylar üzerindeki etkilerinin incelenmesi. (Yüksek lisans Yayınlanmamıș yüksek lisans tezi). Van Yüzüncü Yıl Üniversitesi, Van. (10214486).
Durukan, A., Temur, A., \& Artun, H. (2018). Fen bilimleri ögrretmen adaylarmon sanal gerçeklik destekli mikerö̈gretim uygulamalar: Bir akran degerlendirme çalısması. Paper presented at the 2. Uluslararası Türk Dünyası Eğitim Bilimleri ve Sosyal Bilimler Kongresi, Antalya.

Galvan, J. L., \& Galvan, M. C. (2017). Writing Literature Reviews: A Guide for Students of the Social and Behavioral Sciences: Taylor \& Francis.

Hamidi, F., Ghorbandordinejad, F., Rezaee, M., \& Jafari, M. (2011). A comparison of the use of educational technology in the developed/developing countries. Paper presented at the Procedia Computer Science.

Hew, K. F., \& Cheung, W. S. (2010). Use of three-dimensional (3-D) immersive virtual worlds in K-12 and higher education settings: A review of the research. British Journal of Educational Technology, 41(1), 33-55. doi:10.1111/j.1467-8535.2008.00900.x

Inman, C., Wright, V. H., \& Hartman, J. A. (2010). Use of Second Life in K-12 and higher education: A review of research. Journal of Interactive Online Learning, 9(1), 44-63.

Jensen, L., \& Konradsen, F. (2017). A review of the use of virtual reality head-mounted displays in education and training. Education and Information Technologies, 23(4), 1515-1529. doi:10.1007/s10639-0179676-0

Kavanagh, S., Luxton-Reilly, A., Wuensche, B., \& Plimmer, B. (2017). A systematic review of virtual reality in education. Themes in Science and Technology Education, 10(2), 85-119.

Kim, S. H., Lee, J. L., \& Thomas, M. K. (2012). Between purpose and method: A review of educational research on $3 \mathrm{D}$ virtual worlds. Journal For Virtual Worlds Research, 5(1). doi:10.4101/jvwr.v5i1.2151

Lee, E. A.-L., \& Wong, K. W. (2008). A Review of Using Virtual Reality for Learning. In Z. Pan, A. D. Cheok, W. Müller, \& A. El Rhalibi (Eds.), Transactions on Edutainment I (pp. 231-241). Berlin, Heidelberg: Springer Berlin Heidelberg.

Lee, E. A.-L., Wong, K. W., \& Fung, C. C. (2010). How does desktop virtual reality enhance learning outcomes? A structural equation modeling approach. Computers \& Education, 55(4), 1424-1442. doi:10.1016/j.compedu.2010.06.006.

Linn, M. C. (2003). Technology and science education: starting points, research programs, and trends. International Journal of Science Education, 25(6), 727-758. doi:10.1080/0950069032000076670.

Liu, D., Bhagat, K. K., Gao, Y., Chang, T.-W., \& Huang, R. (2017). The Potentials and Trends of Virtual Reality in Education. In D. Liu, C. Dede, R. Huang, \& J. Richards (Eds.), Virtual, Augmented, and Mixed Realities in Education (pp. 105-130). Singapore: Springer Singapore.

Ma, J., \& Nickerson, J. V. (2006). Hands-on, simulated, and remote laboratories: A comparative literature review. ACM Comput. Surv., 38(3), 7. doi:10.1145/1132960.1132961.

Mikropoulos, T. A., \& Natsis, A. (2011). Educational virtual environments: A ten-year review of empirical research (19992009). Computers \& Education, 56(3), 769-780. doi:10.1016/j.compedu.2010.10.020.

Mora, C. E., Martín-Gutiérrez, J., Añorbe-Díaz, B., \& GonzálezMarrero, A. (2017). Virtual technologies trends in education. Eurasia Journal of Mathematics, Science and Technology Education, 13(1), 469-486. doi:10.12973/eurasia.2017.00626a

Nalbant, G., \& Bostan, B. (2006). Interaction in virtual reality. Paper presented at the 4th International Symposium of Interactive Medial Design (ISIMD).

Nissim, Y., \& Weissblueth, E. (2017). Virtual reality (VR) as a source for self-efficacy in teacher training. International Education Studies, 10(8), 52. doi:10.5539/ies.v10n8p52.

Padilla, M. J. (1990). The science process skills. Retrieved from https://www.narst.org/publications/research/skill.cfm.

Scimago Lab. (2019, 2019/02/22/). SJR - International Science Ranking. Country Rankings. https://www.scimagojr.com/ countryrank.php?area=3300\&categ ory $=3304$.

Trindade, J., Fiolhais, C., \& Almeida, L. (2002). Science learning in virtual environments: a descriptive study. British Journal of Educational Technology, 33(4), 471-488. doi:10.1111/14678535.00283 
Tuysuz, C. (2010). The effect of the virtual laboratory on students' achievement and attitude in chemistry. International Online Journal of Educational Sciences, 2(1), 37-53.

Whitelock, D., Brna, P., \& Holland, S. (1996). What is the value of virtual reality for conceptual learning? Towards a theoretical framework. Paper presented at the Proceedings of the European Conference on Artificial Intelligence in Education, Ediçöes Colibri, Lisboa, Portugal.

Yen, J.-C., Tsai, C.-H., \& Wu, M. (2013). Augmented reality in the higher education: Students' science concept learning and academic achievement in astronomy. Procedia - Social and Behavioral Sciences, 103, 165-173. doi:10.1016/j.sbspro.2013.10.322

Young, S., \& Nichols, H. (2017). A reflexive evaluation of technologyenhanced learning. Research in Learning Technology, 25(0), 13 doi:10.25304/rlt.v25.1998

Yumuşak, A., \& Aycan, Ş. (2002). Fen bilgisi eğitiminde bilgisayar destekli çalışmanın faydaları; Demirci (Manisa)'de bir örnek. M.Ü. Atatürk. Eğitim Fakültesi Eğitim Bilimleri Dergisi, 16, 197-204. 